\title{
Modeling and Simulation Five Level Inverter based UPFC System
}

\author{
S. Muthukrishnan \\ Research Scholar, \\ Department of EEE, Anna University \\ Coimbatore, India
}

\author{
Dr. A.Nirmalkumar \\ Prof and Head / EEE \\ Info Institute of Engineering \\ Coimbatore, India
}

\author{
G. Murugananth \\ Asst. Prof Head / EEE Sri Eswar \\ College of Engineering \\ Coimbatore, India
}

\begin{abstract}
This paper deals with digital simulation of power system using five level inverter based UPFC to improve the power quality. The UPFC is capable of improving transient stability in a power system. It is the most complex power electronic system for controlling the power flow in an electrical power system. The real and reactive powers can be easily controlled in a power system with a UPFC. The circuit model is developed for UPFC using rectifier and inverter circuits. The control angle of the converters is varied to vary the real and reactive powers at the receiving end. The Matlab simulation results are presented to validate the model.
\end{abstract}

\section{Keywords}

UPFC, Power Quality, Statcom, Compensation and matlab simulink

\section{INTRODUCTION}

The power-transfer capability of long transmission lines are usually limited by large signals ability. Economic factors, such as the high cost of long lines and revenue from the delivery of additional power, give strong incentives to explore all economically and technically feasible means of raising the stability limit. On the other hand, the development of effective ways to use transmission systems at their maximum thermal capability has caught much research attention in recent years. Fast progression in the field of power electronics has already started to influence the power industry. This is one direct outcome of the concept of flexible ac transmission systems (FACTS) aspects, which has become feasible due to the improvement realized in power-electronic devices. In principle, the FACTS devices could provide fast control of active and reactive power through a transmission line. The unified power-flow controller (UPFC) is a member of the FACTS family with very attractive features. This device can independently control many parameter, since it has the combined properties of a static synchronous compensator (STATCOM) and static synchronous series compensator (SSSC) [1].

These devices offer an alternative mean to mitigate power system oscillations. Thus, an important question is the selection of the input signals and the adopted control strategy for these devices in order to damp power oscillations in an effective and robust manner. Much research in this domain has been realized [2]-[4]. This research shows that UPFC is an effective device for this purpose.

The UPFC parameters can be controlled in order to achieve the maximal desired effect in solving first swing stability problem.
This problem appears for bulky power systems with long transmission lines.

Various methods to reference identification of the series part, in order to improve the transient stability of the system based on: "optimal parameters"[2], "state variables"[3], and also "injection model" were studied.

This paper is organized as follows. After this introduction, the principle and operation and of a UPFC connected to a network are presented. In section II, the control strategy for UPFC is introduced. Simulation results are presented in sections III. Section IV describes the conclusion.

\section{UPFC SYSTEM}

A simplified scheme of a UPFC connected to an infinite bus via a transmission line is shown in Fig.1.

Using ABCD Parameters

Real Power $\mathrm{P}_{\mathrm{r}}=$

$$
\begin{aligned}
& \qquad \frac{E s E r}{B} \cos (\beta-\alpha)-\frac{A E r^{2}}{B} \cos (\beta-\alpha) \\
& \text { Reactive Power } \mathrm{Q}_{\mathrm{r}}= \\
& \frac{\text { ErEs}}{B} \sin (\beta-\alpha)-\frac{A E r}{B} \sin (\beta-\alpha)
\end{aligned}
$$

Where

$$
\begin{aligned}
& \mathrm{A}=1 \mathrm{~L} 0^{0} \\
& \mathrm{~B}=\mathrm{X} \mathrm{L} 90^{\circ} \\
& \mathrm{C}=0 \\
& \mathrm{D}=1 \mathrm{~L} 0^{\circ}
\end{aligned}
$$

UPFC consists of a parallel and series branches, each one containing a transformer, power-electric converter with turn-off capable semiconductor devices and DC circuit. Inverter 2 is connected in series with the transmission line by series transformer. The real and reactive power in the transmission line can be quickly regulated by changing the magnitude $\left(\mathrm{V}_{\mathrm{b}}\right)$ and phase angle $\left(\delta_{\mathrm{b}}\right)$ of the injected voltage produced by inverter 2 . The basic function of inverter 1 is to supply the real power demanded by inverter 2 through the common DC link. Inverter 1 can also generate or absorb controllable power [5],[6]. 


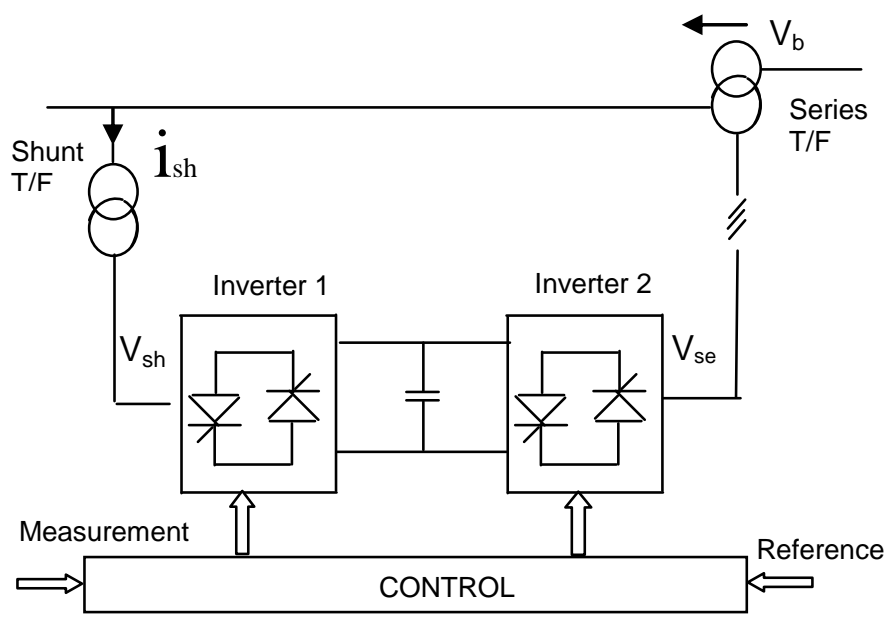

Fig1. UPFC Installed in Transmission Line

The above literature does not deal with UPFC system employing five level inverter. The author is unaware of the use of five level inverter for the application of UPFC. In the present work, five level inverter is proposed in the UPFC system.

\section{SIMULATION RESULTS}

Five level inverter is shown in Fig 2a. Triggering pulses for the devices are shown in Fig 2c. The inverter output voltage is shown in Fig 2c.

Two bus system without compensation circuit is shown in Fig 3a. Sag is produced when an additional load is added. Voltage across loads 1 and 2 are shown in Fig 3b. The real power and reactive power waveforms are shown in Figures $3 \mathrm{c}$ and $3 \mathrm{~d}$ respectively.

Fig 4 shows the line model with UPFC. The UPFC circuit model is shown in Fig 5a. Voltage across loads 1 and 2 are shown in Fig 5b. The RMS voltage is shown in Fig 5c. Real and Reactive powers are shown in Figs $5 \mathrm{~d}$ and $5 \mathrm{e}$ respectively. From the above figures, it can be seen that the sag is mitigated using statcom.

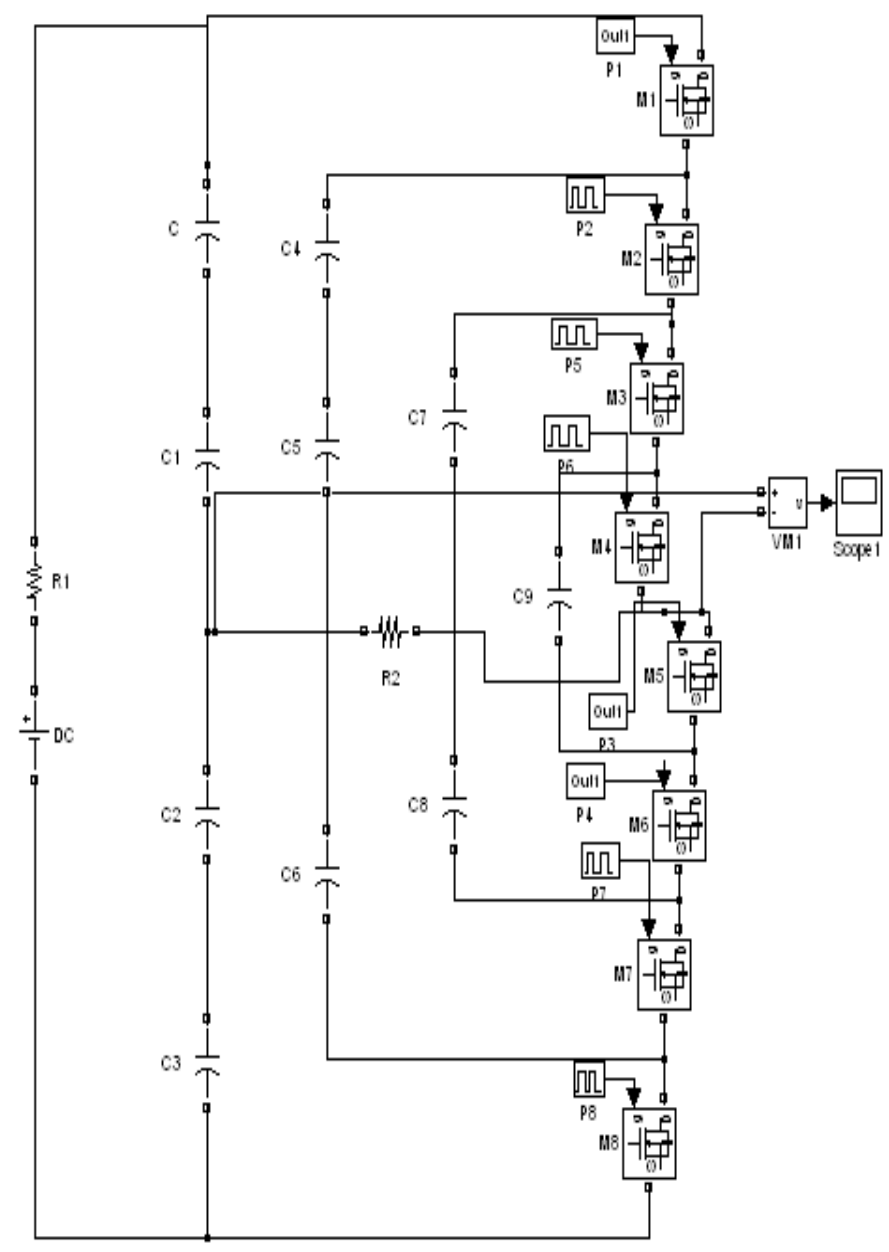

Fig 2a. Five Level inverter

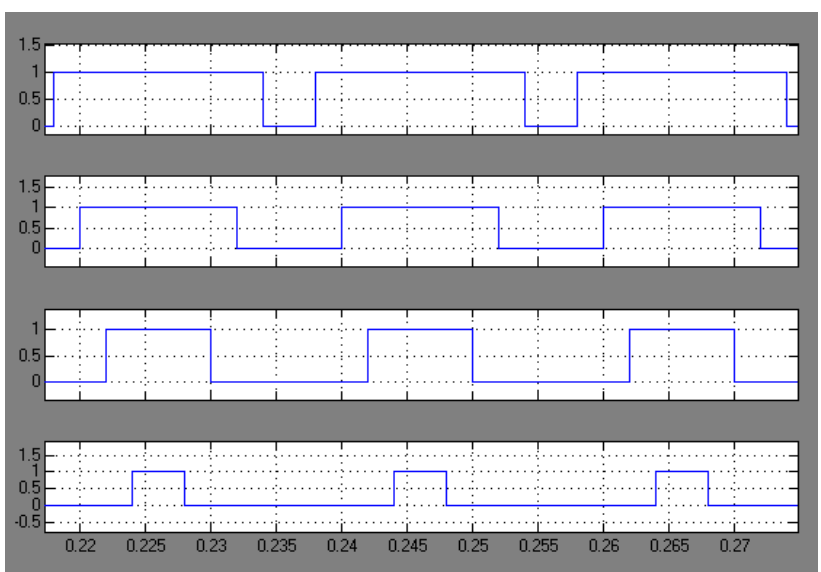

Fig 2b. Driving pulses for M1 ,M2,M3 and M4 


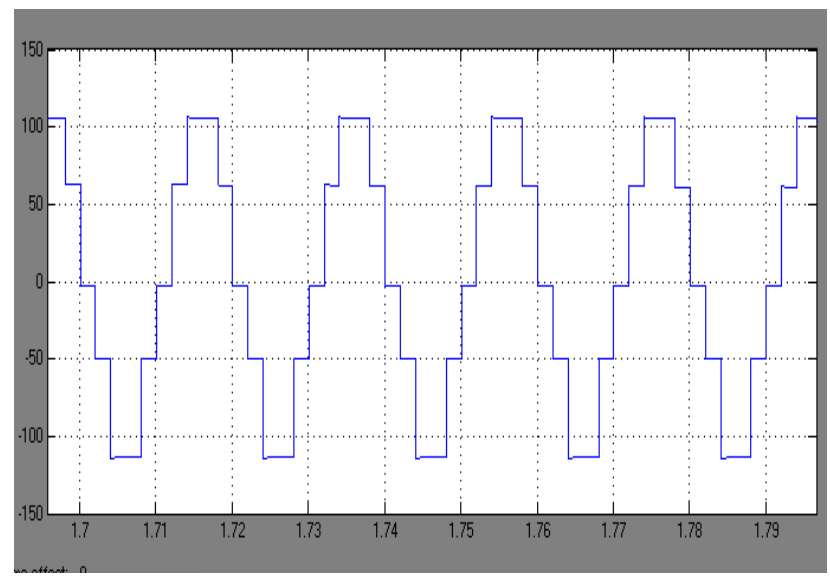

Fig 2c. Inverter output voltage

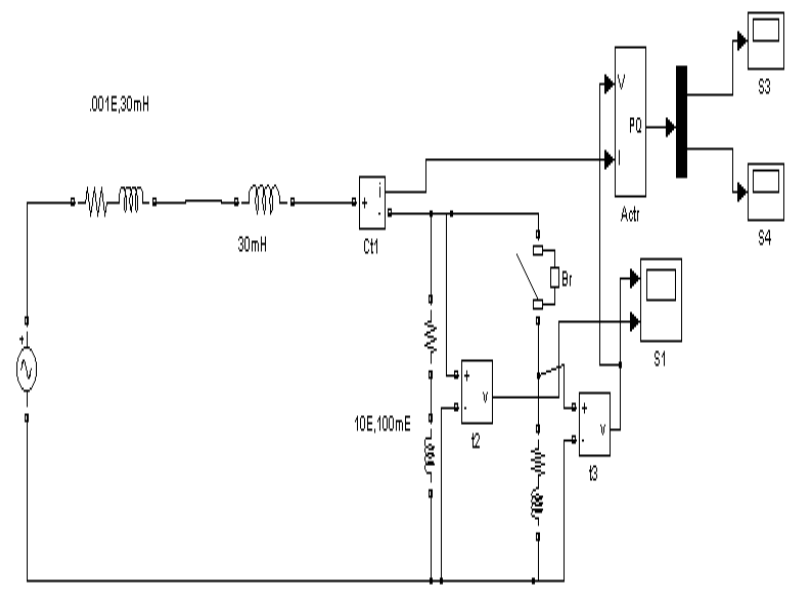

Fig 3a.Line model without compensation circuit

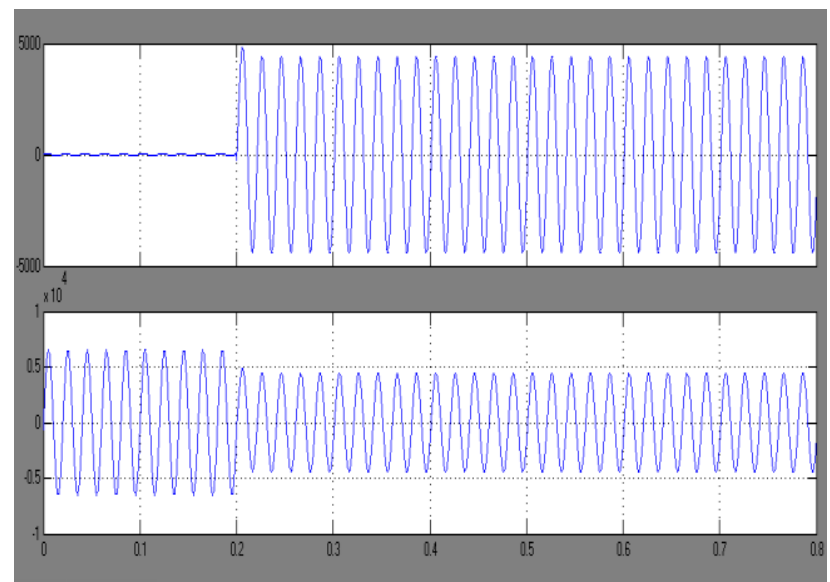

Fig 3b.Voltage across Load-2 and Load-1

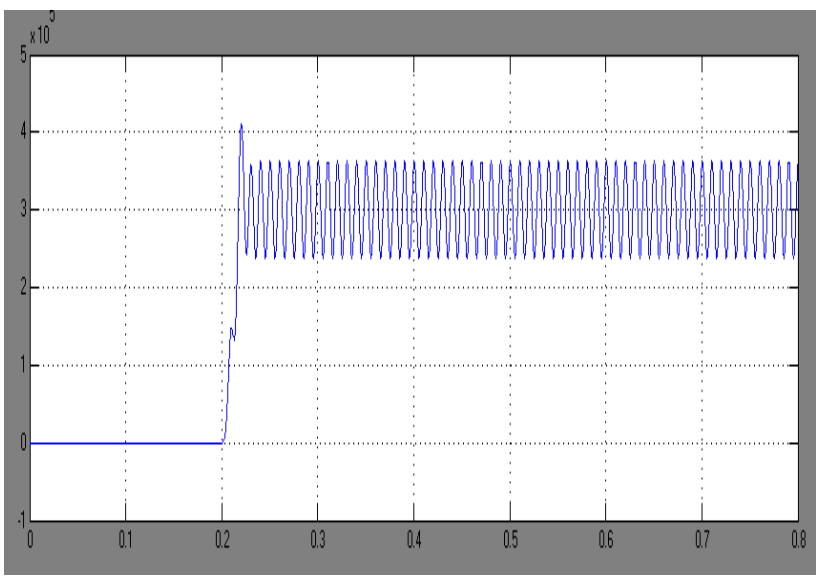

Fig 3c. Real power

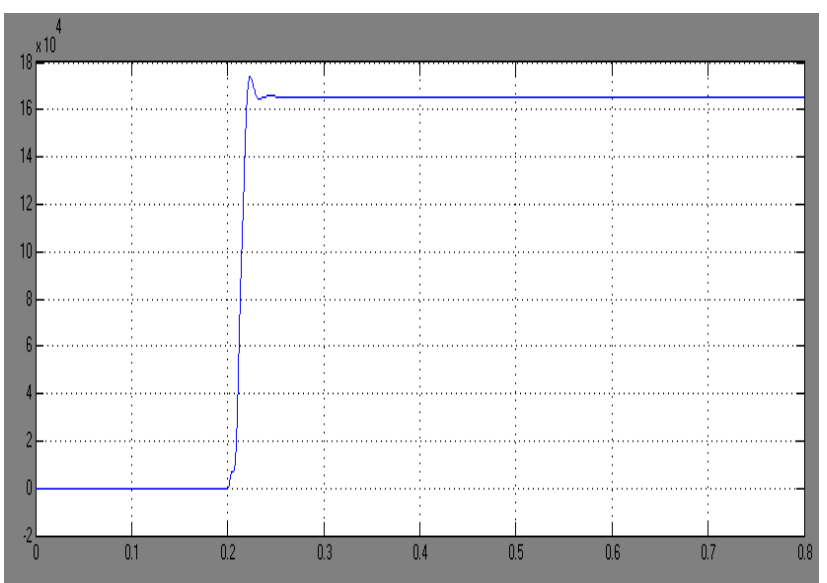

Fig 3d.Reactive power

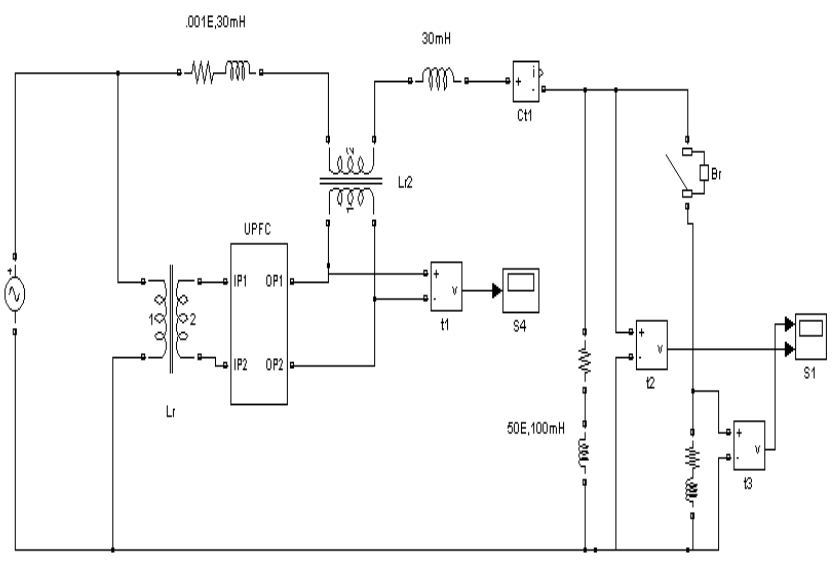

Fig 4. Line model with UPFC 


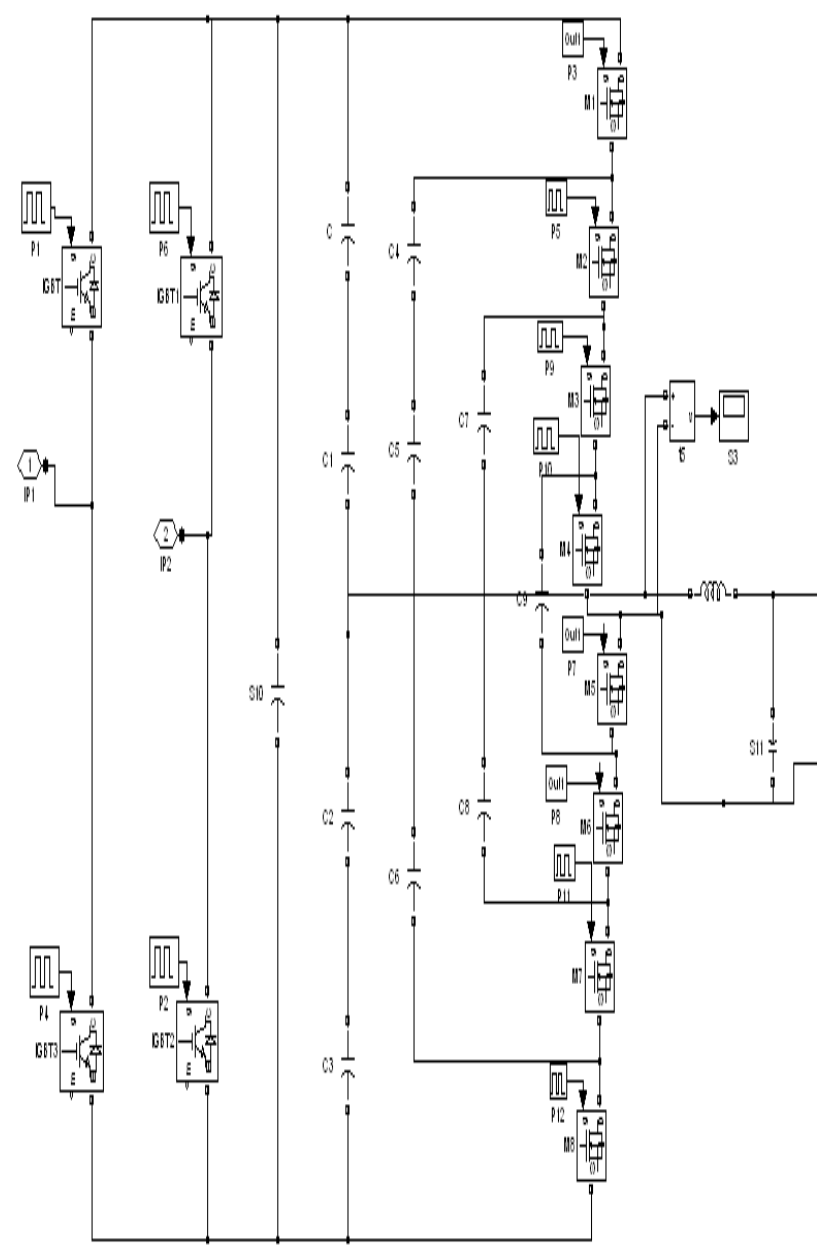

Fig 5a. Circuit model of UPFC

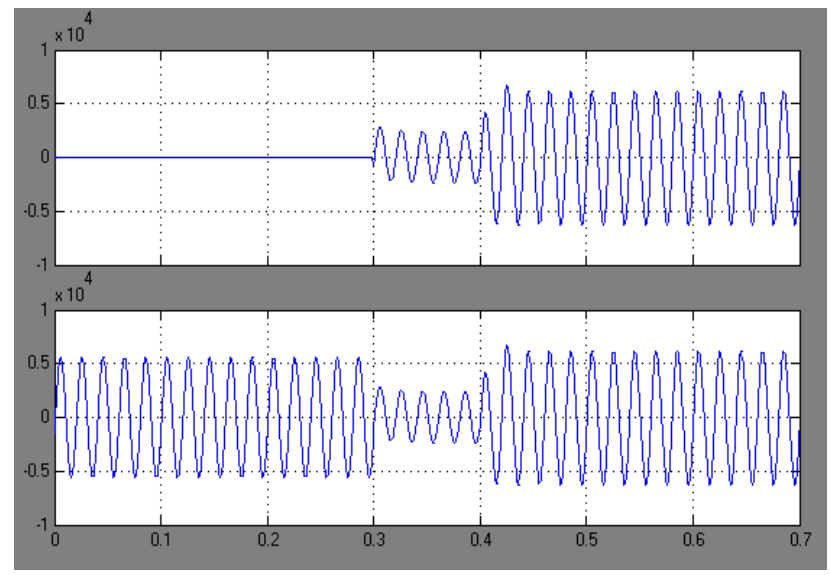

Fig 5b.Voltage across Load -2 and Load -1

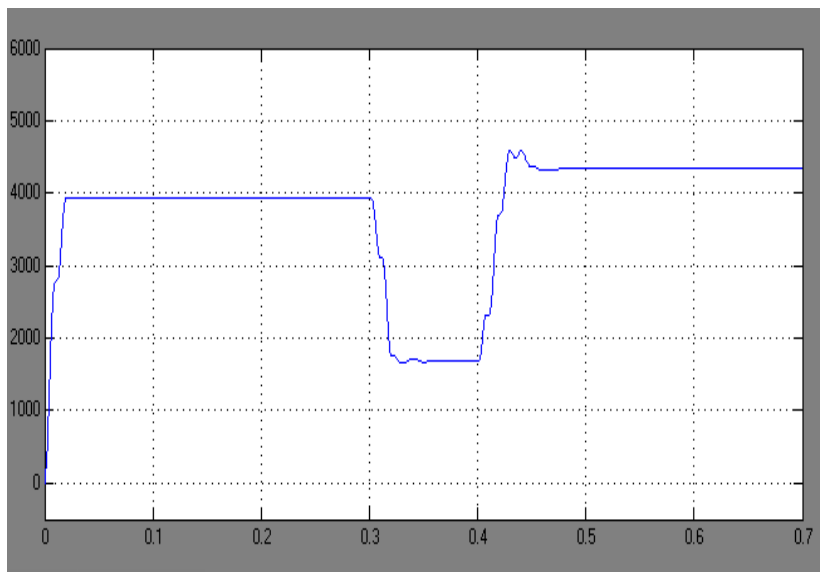

Fig 5c.RMS voltage

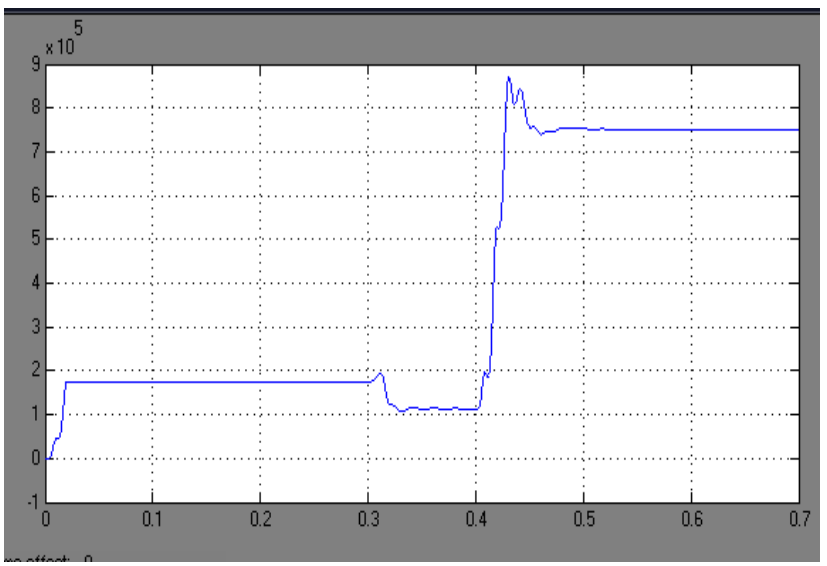

Fig 5d. Real power

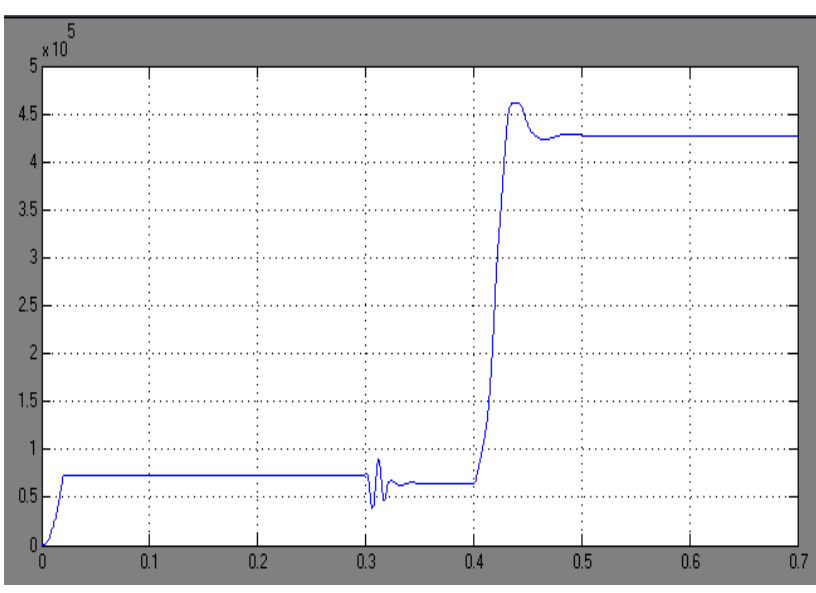

Fig 5e. Reactive power 


\section{CONCLUSION}

In the simulation study, matlab simulink enviroment is used to simulate the model of five level inverter based UPFC. This paper presents the control \& performance of the UPFC used for power quality improvement. Simulation results show the effectiveness of UPFC to control the real and reactive powers. It is found that there is an improvement in the real and reactive powers through the transmission line when UPFC is introduced. The UPFC system has the advantages like reduced hormonics and ability to control real and reactive powers. The heating in the transformer is reduced by using multilevel output. This is due to the reduction in the harmonics. The simulation results are inline with the predictions.

\section{REFERENCES}

[1] C.D. Schaulder et al., "Operation of unified power flow controller (UPFC) under practical constraints', IEEE Trans.Power Del., vol.13, no.2. pp.630-639, Apr1998.

[2] R.Mihalic et al., "Improvement of transient stability using unified power flow controller' IEEE Trans.Power Del., vol. 11, no. 1, pp. 485-492, Jan 1996.

[3] J.Machowski et al., Power System Dynamics and Stability. New York: Wiley, 1998.

[4] M. Noroozian et al., " Improving power system dynamics by series-connected FACTS devices," IEEE trans. Power Del., vol. 139, no.4, pp. 689-694, Oct. 1997.

[5] Gyugyi, “ Unified power-flow control concept for flexible AC transmission system,” Proc. Inst. elect. Eng.C, vol. 139, no.4, pp. 323-331, Jul, 1992.

[6] N.G. Hingorani and L. Gyugyi, Understanding FACTS. New York: IEEE Press, 2000.

[7] E. Gholipour and S.Saadate, "A new method for improving transient stability of power systems by using UPFC," in Proc. European Power Electronics, Toulouse, France, Sep. 2003.

[8] Z. Huang et al.,"Application of UPFC in interconnected power systems- Modeling, interface, control strategy, and case study, “ IEEE Trans. Power Syst., vol. 15, no. 2, pp. 817824, May 2000.
[9] K. Schoder, A, hasanovic, and A. feliachi, " Enhancing transient stability using fuzzy control scheme for the unified power flow controller (UPFC) within the power system toolbox (PST)," in proc. Midwest Symp. Circuits Systems, vol. 3, lansing, MI, Aug, 2000, pp. 1382-1385.

[10] K.K. Sen and A.J.F. Keri, "Comparison of field results and digital simulation results of voltage-sourced converter-based FACTS controller," IEEE Trans. Power Del., vol. 18, no. 1, pp. 300-306, Jan. 2003.

[11] R.Mohan and R.K.Varma, " Thyristor based FACTS controllers for electrical systems transmission “, IEEE press, 2000.

[12] S.Fakuda, Y.Kubo, “ Introduction to series connected multi converter system ”, IEEE, 2002.

\section{AUTHORS PREOFILE}

S.Muthukrishnan has obtained his B.E., degree from Bharathiar University and M.Tech degree from National Institute of Technology, Trichy in the years 1996 and 2004 respectively. He has 12 years of teaching experience. He is presently a research scholar in Anna University. His research area is on power quality improvement using UPFC.

Dr. A. Nirmalkumar has obtained his B.E. degree from Calicut University and M.E. degree from Kerela University in the years 1972 and 1976 respectively. He has completed his Ph.D in the area of Power Electronics from Bharathiar University in the year 1989. He has secured a gold metal from Institution of Engineers in the year 1989. He has 30 years of teaching experience. He is presently working as professor and Head of EEE dept, Info Institute of Engineering, Coimbatore. His research area includes power quality and FACTS devices.

G.Murugananth has obtained his B.E. degree from Madurai Kamarj University and M.E., from Anna University in the years of 2000 and 2009 respectively. He is pursuing his Ph.D., in the area of power electronics and FACTS devices 